\title{
Nephrosphere-Derived Cells Are Induced to Multilineage Differentiation when Cultured on Human Decellularized Kidney Scaffolds
}

Silvia Bombelli, * Chiara Meregalli, * Carla Scalia, * Giorgio Bovo, ${ }^{\dagger}$ Barbara Torsello, ${ }^{*}$ Sofia De Marco, * Massimiliano Cadamuro, * Paolo Viganò, ${ }^{\dagger}$ Guido Strada, ${ }^{\dagger}$ Giorgio Cattoretti, ${ }^{*}$ Cristina Bianchi, ${ }^{*}$ and Roberto A. Perego*

From the School of Medicine and Surgery, ${ }^{*}$ Milano-Bicocca University, Monza; the Urology Unit, ${ }^{\dagger}$ Bassini Hospital, Cinisello Balsamo; and the AnatomoPathology Unit, ${ }^{\ddagger}$ San Gerardo Hospital, Monza, Italy

Accepted for publication September 18, 2017.

Address correspondence to Roberto A. Perego, M.D., School of Medicine and Surgery, Milano-Bicocca University, Via Cadore 48, 20900 Monza, Italy. E-mail: roberto perego@unimib.it.

\begin{abstract}
In end-stage chronic kidney disease, the option of organ transplantation is limited because of the scarce availability of kidneys. The combination of stem cell research, regenerative medicine, and tissue engineering seems a promising approach to produce new transplantable kidneys. Currently, the possibility to repopulate naturally obtained scaffolds with cells of different sources is advancing. Our aim was to test, for the first time, whether the nephrosphere (NS) cells, composed by renal stem/progenitorlike cells, were able to repopulate different nephron portions of renal extracellular matrix scaffolds obtained after decellularization of human renal tissue slices. Our decellularization protocol enabled us to obtain a completely acellular renal scaffold while maintaining the extracellular matrix structure and composition in terms of collagen IV, laminin, and fibronectin. NS cells, cultured on decellularized renal scaffolds with basal medium, differentiated into proximal and distal tubules as well as endothelium, as highlighted by histology and by the specific expression of epithelial cytokeratin 8.18, proximal tubular CD10, distal tubular cytokeratin 7, and endothelial von Willebrand factor markers. Endothelial medium promoted the differentiation toward the endothelium, whereas epithelial medium promoted the differentiation toward the epithelium. NS cells seem to be a good tool for scaffold repopulation, paving the way for experimental investigations focused on whole-kidney reconstruction. (Am J Pathol 2018, 188: 184-195; https://doi.org/10.1016/j.ajpath.2017.09.012)
\end{abstract}

Kidney diseases are considered a global public health issue, given their worldwide incidence and associated morbidity and mortality, affecting approximately $8 \%$ to $16 \%$ of the adult population. ${ }^{1}$ The only therapeutic options for patients with end-stage renal disease are lifelong dialysis treatment or organ transplantation. Advances in the understanding of the mechanisms of rejection, as well as the development of new immunosuppressant therapies, have led to an increase of the number of patients eligible for renal transplantation, although the availability of donors has remained stable. Consequently, in renal diseases, the need for kidneys is urgent and the hope is that this need can be fulfilled by stem cell and regenerative medicine approaches. For this purpose, the interactions between the study of renal stem cells for regenerative medicine and tissue engineering are fundamental to produce new transplantable organs. Bussolati and
Camussi $^{2}$ recently reviewed different types of renal progenitor cells that were successfully engrafted into the renal tissue in animal models of acute injury. Nevertheless, the action of these progenitor cells in models of chronic renal diseases, in which new nephrons have to be generated to compensate their loss, has still to be disclosed.

In recent years, tissue engineering research focused its attention on scaffolds of natural extracellular matrix (ECM), obtained by removing cellular components from the native

\footnotetext{
Supported by Ministero dell'Istruzione, dell'Università e della Ricerca grant 669373 (R.A.P.); Milano-Bicocca University grants 0260 and 0159 (R.A.P.); Associazione Gianluca Strada Onlus grant 792010100-2 (R.A.P.); and Ministero dell'Istruzione, dell'Università e della Ricerca Postdoctoral Fellowships (S.B. and M.C.) and Ph.D. Fellowships (C.M. and S.D.M.)

Disclosures: None declared.
} 
organs by a decellularization process. Decellularized kidney scaffolds have been obtained from rats, ${ }^{3-6}$ pigs, ${ }^{3,6-10}$ nonhuman primates, ${ }^{11,12}$ and cadaveric human kidneys ${ }^{3}$ lacking the transplantation criteria. ${ }^{13-15}$ Attempts of cellular repopulation have been performed in both perfusion and static cultures using different cell types, such as rat neonatal kidney cells, human umbilical vein endothelial cells, ${ }^{3}$ mouse kidney stem cells, ${ }^{6}$ mouse embryonic stem cells, ${ }^{4,16-18}$ human embryonic stem cells, ${ }^{19}$ human induced pluripotent stem cells (iPS)-derived renal progenitor cells, ${ }^{20}$ and human iPS-derived endothelial cells. ${ }^{6}$ Although the decellularized ECM scaffolds could also be useful for assessing the capability of the adult renal stem/progenitor cells to regenerate whole nephrons, no attempts of repopulation of decellularized natural human kidney ECM scaffold with adult human renal stem/progenitor cells have been performed until now.

We have previously identified a population of renal stemlike cells in clonal human nephropsheres (NSs), ${ }^{21}$ and with these NS cells, it is possible to generate three-dimensional (3D) tubular-like structures in 3D cultures and in vivo under the renal capsule of nude mice. ${ }^{21}$ In the present article, we wanted to investigate the differentiation abilities of NS cells and their capability to repopulate different nephron portions when cultured on renal ECM scaffolds obtained by decellularization of human renal tissue slices.

\section{Materials and Methods}

\section{Tissues}

Normal kidney tissue was obtained from 18 patients (11 males and 7 females; age range, 48 to 84 years) after nephrectomy because of the presence of renal tumors. The normal tissue was taken from a healthy region of the kidney, without any indication of cancer, opposite to the tumor and exceeding the diagnostic needs. All procedures were performed after written patient consent was obtained and were approved by the local ethical committee. NS cultures were established from all fresh renal tissue samples. The remaining part of all tissue samples was formalin fixed, paraffin embedded (FFPE). Frozen pieces of renal tissue, comprising cortex, medulla, and papilla, were stored at $-80^{\circ} \mathrm{C}$ until use.

\section{Nephrosphere Cultures}

The single-cell suspension from renal tissue $\mathrm{e}^{22}$ and the NS cultures $^{21}$ were obtained from 12 different tissue samples, as described. The suspension obtained after mechanical dissociation and enzymatic digestion was sieved through a $250-\mu \mathrm{m}$ cell strainer and then passed through a pipette syringe to obtain a single-cell suspension. ${ }^{21}$ Red blood cells were removed by hemolysis with $0.8 \% \mathrm{NH}_{4} \mathrm{Cl}$ solution for 5 minutes. After a 24- to 48-hour adhesion step, the trypsinized bulk epithelial cells were plated $(10,000$ cells $/ \mathrm{mL})$ in stem cell medium on Poly-HEMA (Sigma-Aldrich, St.
Louis, MO), or $1 \%$ agarose, coated dishes in nonadherent conditions for the formation of floating NS. After 10 to 12 days, NSs were collected for use. ${ }^{21}$ When necessary, NS cells were dissociated enzymatically for 5 minutes in TrypLE Express (Life Technologies, Waltham, MA) and then mechanically by repetitive pipette syringing to generate a single-cell suspension.

\section{Immunofluorescence and FACS Analysis}

Immunofluorescence on floating NS cells obtained from three different tissue samples was performed by fixing the spheres in $4 \%$ paraformaldehyde for 20 minutes, blocking for 20 minutes with phosphate-buffered saline (PBS) containing $0.1 \%$ bovine serum albumin (Sigma-Aldrich) and 0.3\% Triton X-100 (Sigma-Aldrich), and then incubating with the specific primary antibody overnight at $4^{\circ} \mathrm{C}$. The primary antibodies used are the following: rabbit anti-von Willebrand factor (vWf; 1:2000; Dako, Copenhagen, Denmark), rabbit monoclonal anticytokeratin (CK) 7 (1:200; clone EPR1619Y; Abcam, Cambridge, UK), mouse monoclonal anti-CK8.18 (1:50; clone 5D3; Thermo Fisher Scientific, Waltham, MA), rabbit anti-paired box 2 (1:50; Thermo Fisher Scientific), mouse monoclonal anti-N-cadherin (1:100; clone 32; Becton Dickinson, San Jose, CA), and rabbit anti-E-cadherin (1:50; Cell Signaling Technology, Danvers, MA). For the secondary antibody, spheres were incubated with Alexa Fluor 594-conjugated anti-mouse or Alexa Fluor 488-conjugated anti-rabbit IgG antibodies (Molecular Probes Invitrogen, Waltham, MA) for 1 hour. The spheres were resuspended with ProLong Gold Antifade with DAPI (Molecular Probes Invitrogen), and the slides were mounted. Immunofluorescence of cells obtained after dissociation of NS cells from three tissue samples was performed on a cytospinned preparation, as described. ${ }^{22}$ Immunofluorescence micrographs were obtained at $\times 400$ magnification using a Zeiss LSM710 confocal microscope and Zen software version 2009 software (Zeiss, Oberkochen, Germany). Fluorescenceactivated cell sorting (FACS) staining was performed, as described, ${ }^{22,23}$ on four different NS samples and analyzed on 20,000 events with a MoFlo Astrios cell sorter software and Kaluza software version 1.3 (both from Beckman Coulter, Miami, FL). For FACS analysis, the following antibodies were used: rabbit monoclonal anti-CK7 (1:20; clone EPR1619Y; Abcam), mouse monoclonal fluorescein isothiocyanate-conjugated anti-CK (1:10; clone CK3-6H5; Miltenyi Biotec, Auburn, CA), mouse monoclonal phosphatidylethanolamine-conjugated anti-CD13 (1:10; clone WM15; Biolegend, San Diego, CA), mouse monoclonal APCH7-conjugated anti-CD10 (1:20; clone HI10a; Becton Dickinson), and mouse anti-prominin 2 (1:10; Neuromics, Edina, $\mathrm{MN}$ ).

\section{Decellularization}

A total of 12 different frozen renal tissues were cut into slices (approximately $2 \mathrm{~mm}$ thick), maintaining all kidney 
regions. Slices were decellularized using a modification of two published methods. ${ }^{3,7}$ The slices were washed with $2 \times$ PBS supplemented with penicillin and streptomicin for 15 minutes, followed by 1 hour of $0.02 \%$ trypsin, 2 hours of $2 \%$ Tween-20, 3 hours of $4 \%$ sodium deoxycholate, and $1 \%$ SDS (all from Euroclone, Milan, Italy) overnight treatment. After each step, the slices were washed with $2 \times$ PBS for 15 minutes. Every step and wash was performed under agitation. At the end of decellularization treatments, the slices were subjected to washes with $2 \times$ PBS containing penicillin and streptomicin for 4 hours and then with $1 \times$ PBS containing penicillin and streptomicin for another 4 hours.

\section{Decellularized Scaffold Analysis}

Native and decellularized FFPE tissue samples were divided into sections ( $2 \mu \mathrm{m}$ thick), deparaffinized, and then stained with hematoxylin and eosin (H\&E), trichrome, or Alcian blue/periodic acid-Schiff (all from Sigma-Aldrich). Images were acquired using the ScanScope CS System (Aperio Technologies, Wetzlar, Germany) equipped with ImageScope software (Aperio Technologies). For immunohistochemical analysis, the sections were deparaffinized, subjected to specific antigen retrieval, and blocked with human serum for 2 hours at room temperature. Staining was performed overnight at $4^{\circ} \mathrm{C}$ with the following antibodies: rabbit anti-type IV collagen (1:100; Thermo Fisher Scientific; $0.5 \% \mathrm{SDS} / 50 \mathrm{mmol} / \mathrm{L}$ 2-mercaptoethanol, 10 minutes at $95^{\circ} \mathrm{C} ; 10 \mathrm{mmol} / \mathrm{L}$ EDTA in Tris buffer, $\mathrm{pH} 8 ; 8$ minutes at $800 \mathrm{~W}$ and 20 minutes at $600 \mathrm{~W}$ for antigen retrieval); and rabbit anti-laminin (1:50; Dako; proteinase K, 5 minutes at $37^{\circ} \mathrm{C}$ for antigen retrieval); rabbit anti-fibronectin [1:2000; Dako; Retrieval 2 (Covance, Princeton, NJ), 20 minutes in the steamer and 20 minutes at room temperature for antigen retrieval]. Renal sections were rinsed with $0.05 \%$ Tween-20 in PBS and incubated for 30 minutes at room temperature with the appropriate Dako EnVision anti-rabbit antibody. Specimens were developed using $0.04 \mathrm{mg} / \mathrm{mL}$ 3,3-diaminobenzidine tetrahydrochloride (Sigma-Aldrich) along with $0.01 \% \mathrm{H}_{2} \mathrm{O}_{2}$ and were counterstained with hematoxylin. All of the antibodies were diluted in PBS supplemented with 5\% normal human serum type 0 and $0.05 \%$ Tween-20 (Euroclone). For the quantitative evaluation of ECM proteins, immunofluorescence was performed by using Alexa Fluor 594 goat anti-rabbit (Molecular Probes Invitrogen). Three different specimens of native kidney and the corresponding decellularized scaffolds were stained, and three different fields for each antibody were acquired at $\times 40$ magnification and then analyzed for the quantification of ECM protein with ImageJ software version $1.48 \mathrm{v}(\mathrm{NIH}$, Bethesda, MD; http://imagej.nih.gov/ij), as described. ${ }^{24}$

\section{DNA Quantification}

DNA was extracted from native and decellularized renal slices, obtained from three different renal samples with the
QIamp DNA Mini Kit (Qiagen, Venlo, the Netherlands), according to the manufacturer's instructions, and quantified using Nanodrop (Life Technologies).

\section{Nephrosphere Culture on Decellularized ECM Scaffolds}

Fifty thousand alive cells obtained by enzymatic and mechanic dissociation from different NS samples $^{21}$ were seeded on the decellularized renal scaffolds, obtained from the same patient, and cultured with basal medium or specific cell differentiation media in 24-well Poly-HEMA coated plates. Ten different experiments were performed, with each experiment representing one individual patient. The basal medium was Dulbecco's modified Eagle's medium low glucose (Euroclone) supplemented with 10\% fetal bovine serum (Euroclone). The specific media were as follows: epithelial medium, composed of Dulbecco's modified Eagle's medium-F12 (Lonza, Basel, Switzerland) supplemented with $10 \%$ fetal bovine serum, ITS supplement $(5 \mu \mathrm{g} /$ $\mathrm{mL}$ insulin, $5 \mu \mathrm{g} / \mathrm{mL}$ transferrin, and $5 \mathrm{ng} / \mathrm{mL}$ sodium selenite), $36 \mathrm{ng} / \mathrm{mL}$ hydrocortisone, and $40 \mathrm{pg} / \mathrm{mL}$ triiodothyronine (all from Sigma-Aldrich), $20 \mathrm{ng} / \mathrm{mL}$ endothelial growth factor (Cell Signaling Technology), and $50 \mathrm{ng} / \mathrm{mL}$ hepatocyte growth factor (Cell Signaling Technology); and endothelial medium, composed of endothelial basal medium (Lonza) supplemented with $10 \%$ fetal bovine serum and $10 \mathrm{ng} / \mathrm{mL}$ vascular endothelial growth factor (Miltenyi Biotec). In all differentiating conditions, the cells were allowed to attach to the ECM scaffold for 5 days while only adding the medium, without changing.

The cultures were stopped at different time points, formalin fixed for at least 16 hours, and paraffin embedded for histological analysis.

\section{D Staining of Cultured Scaffolds}

At $4,7,15$, and 30 days, a small portion of three different cultured scaffolds was cut and fixed in formalin for 1 hour. The scaffolds were then incubated with Alexa Fluor 680-phalloidin (1:100 in PBS; Molecular Probes Invitrogen) for 15 minutes and with DAPI (Sigma-Aldrich) for 10 minutes, and then mounted between a glass coverslip and glass slides. Immunofluorescence micrographs were obtained at $\times 400$ magnification using the Zeiss LSM710 confocal microscope and Zen2009 software. Z-stack function was used to acquire sequential micrographs every 1.5 or $2 \mu \mathrm{m}$, covering the entire thickness of the chosen structures, and then $3 \mathrm{D}$ reconstructions were performed using the specific ImageJ software plugin.

\section{Histological Characterization}

The decellularized scaffolds cultured with NS cells were FFPE, divided into section ( $2 \mu \mathrm{m}$ thick), and H\&E stained for cellular repopulation assessment and evaluation of morphological features of the formed structures. Images 

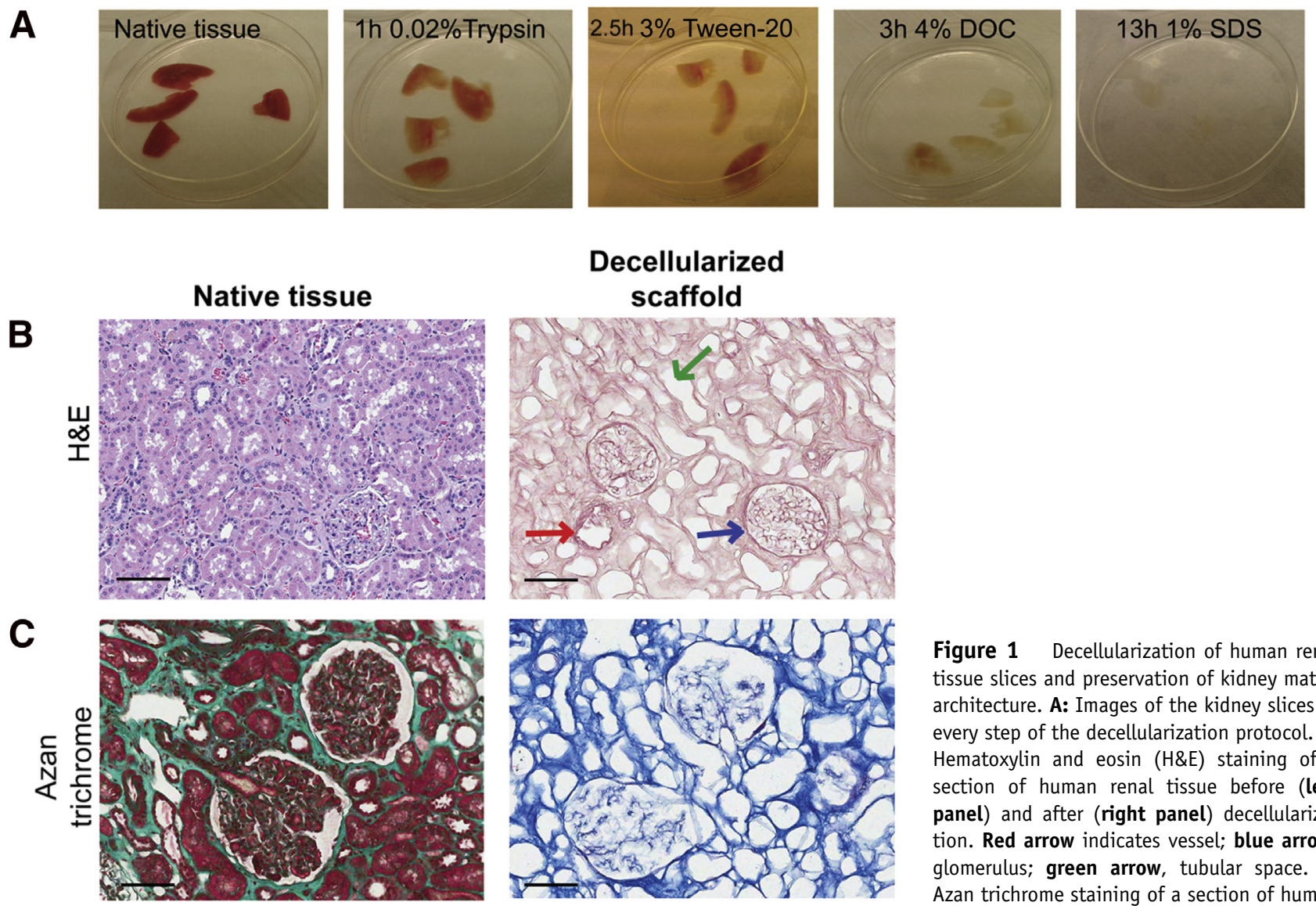

\section{Decellularized scaffold}

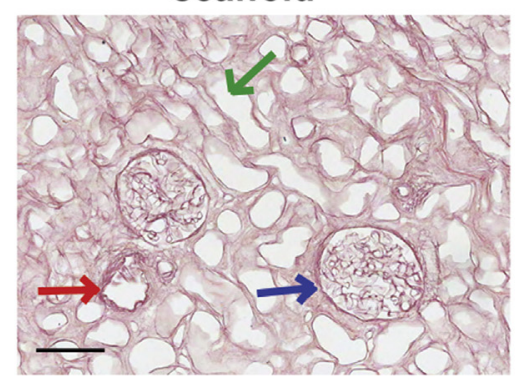

D
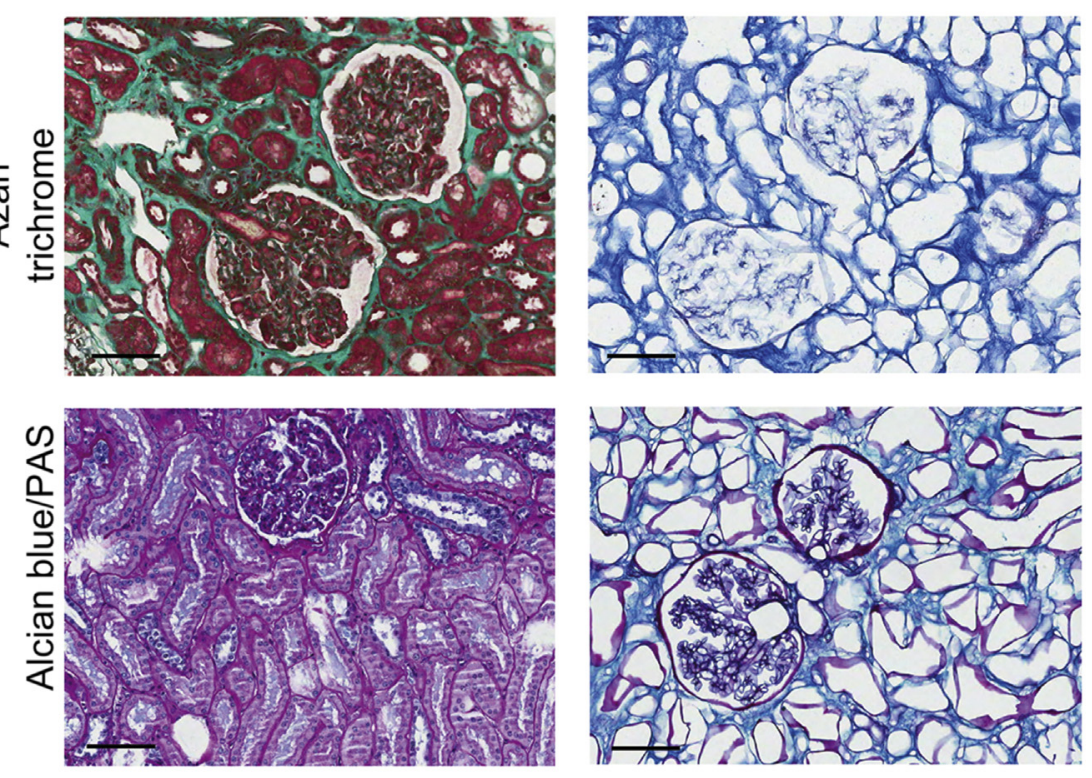

Figure 1 Decellularization of human renal tissue slices and preservation of kidney matrix architecture. A: Images of the kidney slices at every step of the decellularization protocol. B: Hematoxylin and eosin (H\&E) staining of a section of human renal tissue before (left panel) and after (right panel) decellularization. Red arrow indicates vessel; blue arrow, glomerulus; green arrow, tubular space. C: Azan trichrome staining of a section of human renal tissue before (left panel) and after

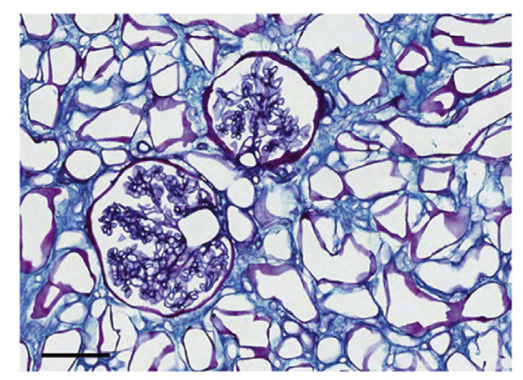
(right panel) decellularization. D: Alcian blue/ periodic acid-Schiff (PAS) staining of section of human renal tissue before (left panel) and after (right panel) decellularization. E: DNA quantification comparison between native kidney tissue and decellularized scaffolds. Data are expressed as means \pm SD (E). $n=3$ independent experiments (E). ${ }^{* * *} P<0.001$. Scale bars $=200 \mu \mathrm{m}(\mathbf{B}-\mathbf{D})$. Original magnification, $\times 100 \quad$ (B-D). DOC, sodium deoxycholate.

E

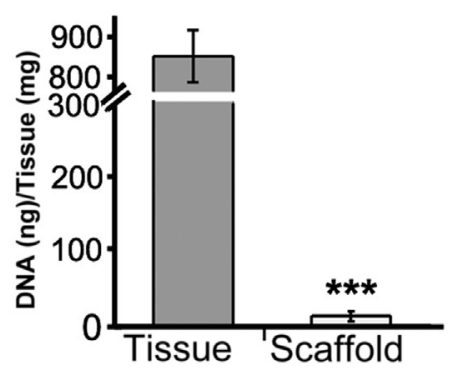

were acquired using the ScanScope CS System equipped with ImageScope software. Immunofluorescence staining was performed, as described, ${ }^{25,26}$ on FFPE sections using the following antibodies: rabbit monoclonal anti-Ki-67, a marker of cell proliferation (1:100; clone SP6; Thermo Fisher Scientific); mouse monoclonal anti-CD10, a proximal tubular marker (1:100; clone 56C6; Leica Biosystems, Wetzlar, Germany); rabbit monoclonal anti-CK7, a distal tubular marker (1:200; clone EPR1619Y; Abcam); mouse monoclonal anti-calbindin-D28k, a distal tubular marker (1:1000; clone CB-955; Sigma-Aldrich); mouse monoclonal anti-CK8.18, an epithelial marker (1:50; clone 5D3; Thermo 
A
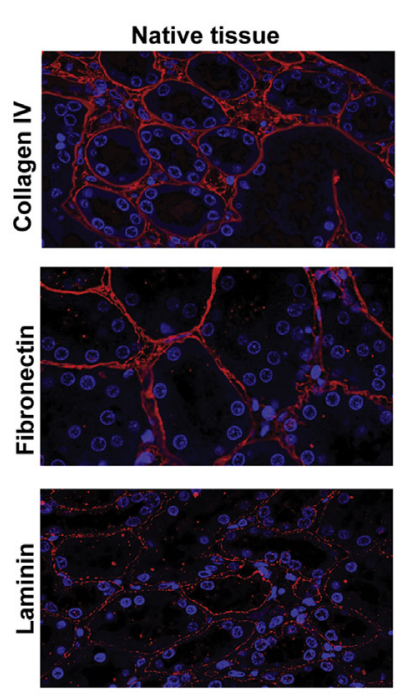

B
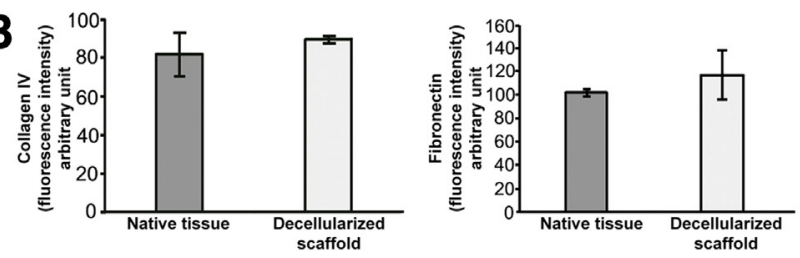

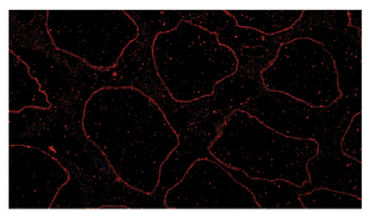

Decellularized

scaffold
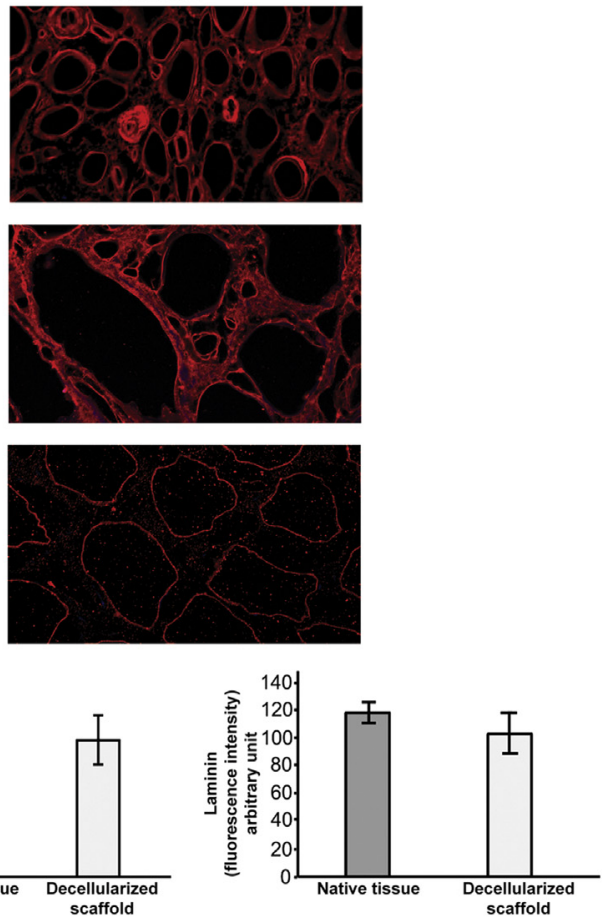

Figure 2 Extracellular matrix (ECM) protein evaluation. A: Representative immunofluorescence images of collagen IV, fibronectin, and laminin (red) in human renal tissue sections before (left column) and after (right column) decellularization. Blue: DAPI. B: Quantitative analysis of ECM proteins based on immunofluorescence staining. Data are expressed as means \pm SD (B). $n=3$ different fields for each sample (three independent experiments; $\mathbf{A}$ and $\mathbf{B}$ ). Original magnification, $\times 400(A)$.
Fisher Scientific); rabbit polyclonal anti-vWf endothelial marker (1:2000; Dako); mouse monoclonal anti-E-cadherin, a distal tubular marker (1:100; clone NCH-38; Dako); mouse monoclonal anti-N-cadherin, a proximal tubular marker (1:200; Thermo Fisher Scientific); mouse monoclonal anti-CD133, a marker of parietal cells of the Bowman capsule (1:100; Miltenyi Biotec); and rabbit polyclonal anti-cleaved caspase 3, a marker of apoptosis (1:300; Cell Signaling Technology). Sections were subjected to a preconditioning treatment for antigen relaxing ${ }^{25}$ by incubation in a $0.5 \% \mathrm{SDS}, 50 \mathrm{mmol} / \mathrm{L}$ 2-mercaptoethanol (Merck, Darmstadt, Germany) modified Laemmli buffer at $95^{\circ} \mathrm{C}$ for 10 minutes. After appropriate antigen retrieval $[10 \mathrm{mmol} / \mathrm{L}$ EDTA in Tris buffer, $\mathrm{pH} 8,8$ minutes at $800 \mathrm{~W}$ and 20 minutes at $600 \mathrm{~W}$, except for cleaved caspase 3 (ie, 20 $\mathrm{mmol} / \mathrm{L}$ citrate, 20 minutes in the steamer and 20 minutes at room temperature)], the slides were incubated with the specific diluted antibodies overnight in a humidity chamber at $4{ }^{\circ} \mathrm{C}$, followed by incubation with Alexa Fluor 594 goat anti-rabbit and Alexa Fluor 680 goat anti-mouse secondary antibodies (Molecular Probes Invitrogen). Primary and secondary antibodies were diluted in tris-buffered saline containing $2 \%$ bovine serum albumin and $10 \%$ lactose. ${ }^{27}$ Sections were mounted with ProLong Gold Antifade with DAPI for nuclear counterstaining. Immunofluorescence micrographs were obtained at $\times 400$ magnification using a Zeiss LSM710 confocal microscope and Zen software version 2009 or using the Hamamatsu Nanozoomer S60 scanner (Nikon, Campi Bisenzio, Italy) equipped with NDP.view2 software to acquire images of the entire slices.
FFPE sections ( $2 \mu \mathrm{m}$ thick) of renal tissue were processed, as described above, and used as positive controls. In the case of sequential staining, after the first staining, the sections were subjected to antibody elution by incubation in a shaking water bath at $56^{\circ} \mathrm{C}$ for 30 minutes in a $2 \%$ SDS, 114 $\mathrm{mmol} / \mathrm{L}$ 2-mercaptoethanol, $60 \mathrm{mmol} / \mathrm{L}$ Tris- $\mathrm{HCl}, \mathrm{pH} 6.8$, solution. ${ }^{26}$

\section{Statistical Analysis}

The unpaired two-tailed $t$-test was used to analyze statistical differences, and $P<0.05$ was considered significant.

\section{Results}

\section{Kidney Decellularization and Scaffold Characterization}

Decellularization of human kidney slices was performed by a four-step protocol, obtaining transparent slices of acellular scaffold (Figure 1A). H\&E staining showed eosinophil staining, typical of collagen, and no basophilic nuclear outlines were detected (Figure 1B). Trichrome (Figure 1C) and Alcian blue/periodic acid-Schiff (Figure 1D) staining showed the preservation of collagen and glycosaminoglycans, respectively. Furthermore, the decellularization treatment resulted in the preservation of the renal architecture, with blood vessels, glomeruli, and tubular spaces (Figure 1B). The quantification of DNA extracted from three samples of native and decellularized kidney tissue was used to assess the decellularization status. There was a significant $(P<0.001)$ 


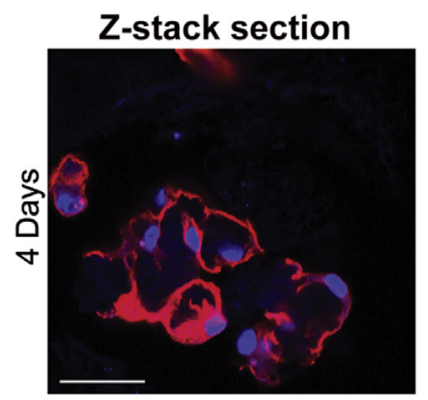

\section{D Reconstruction}
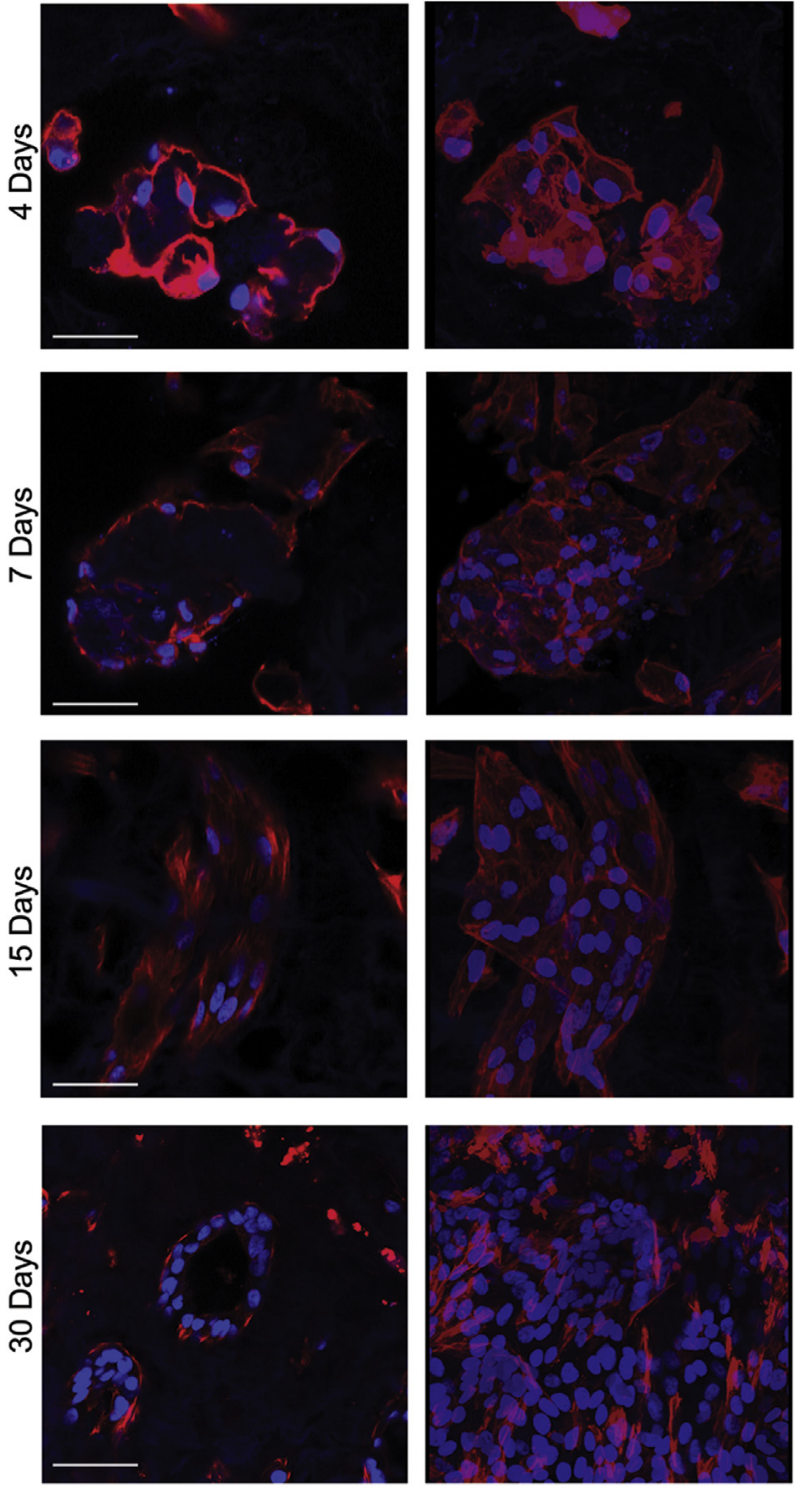

Figure 3 Three-dimensional (3D) staining of scaffolds repopulated with nephrosphere (NS) cells. Representative images of DAPI (blue) and phalloidin (red) immunofluorescence staining of the scaffolds at 4, 7, 15, and 30 days after seeding NS cells. Chosen Z-stack sections (left column) and 3D reconstruction (right column). Total thicknesses of the different structures shown at the indicated time points were as follows: 4 days, $70.73 \mu \mathrm{m} ; 7$ days, $73.5 \mu \mathrm{m} ; 15$ days, $48 \mu \mathrm{m}$; and 30 days, $46 \mu \mathrm{m}$. Scale bars $=50 \mu \mathrm{m}$. Original magnification, $\times 400$.

reduction of DNA content $(98.5 \%)$ in decellularized scaffolds (means $\pm \mathrm{SD}, 11.63 \pm 6.80 \mathrm{ng} / \mathrm{mg}$ tissue) with respect to the native kidney (means $\pm \mathrm{SD}, 803.3 \pm 128.5 \mathrm{ng} / \mathrm{mg}$ tissue) (Figure 1E).

\section{Decellularized Scaffold Composition}

The decellularization did not alter the ECM composition. Type IV collagen, laminin, and fibronectin showed similar patterns in decellularized slices and native kidneys (Figure 2).
In the scaffolds, immunohistochemical staining showed a continuous network of collagen IV and fibronectin in the tubular and glomerular basement membrane, whereas the laminin signal seemed to be more intense in the vascular and glomerular basement membrane (Supplemental Figure S1A). Moreover, immunofluorescence staining of the decellularized scaffold showed that laminin appeared organized in multiple layers in a ring-like pattern in the vascular basement membrane and more concentrated than in the tubular basement membrane (Supplemental Figure S1B). Quantitative analysis of ECM proteins with ImageJ software after immunofluorescence staining did not demonstrate any significant difference between the decellularized scaffolds and native kidneys (Figure 2).

\section{Scaffold Repopulation with Nephrosphere Cells}

Fifty thousand cells obtained after dissociation of NS cells ${ }^{21}$ were seeded onto slices of decellularized scaffolds in 24well Poly-HEMA coated plates. Poly-HEMA was necessary to avoid the attachment of cells to the plastic. After 5 days, no cells were observed in the free area of the well not covered by the scaffold, and at this point, the medium was completely changed for the first time. 3D staining of small scaffold portions cultured with basal medium showed, at 4 , 7,15 , and 30 days, the presence of cells able to proliferate and repopulate the decellularized scaffold, demonstrating the nontoxicity of the decellularized matrix and the capability of the NS cells to attach and proliferate into the scaffolds (Figure 3). The largest parts of the scaffolds were processed for histological characterization. H\&E staining confirmed the presence of seeded cells at 30 days of culture (Figure 4, A-C) in all three different culture media tested. NS cells cultured in basal medium, without any growth factor stimulating a specific differentiation, could attach in different regions of the nephron, such as the tubular, vascular, and glomerular spaces. H\&E staining showed the presence of simple cuboidal epithelial-like cells, typical of the renal tubular portion (Figure 4A), as well as simple, squamous, epithelial-like cells lining the Bowman capsule and the glomerulus (Figure 4A). Flat cells, similar to simple, squamous, epithelial-like cells, can be also observed in other portions of the scaffold, in particular located on the big vessel basement membrane (Figure 4A). NS cells cultured in endothelial medium seemed to preferentially attach to the vascular spaces, with the H\&E staining showing the presence of simple, squamous, endothelial-like cells only (Figure 4B). Neither any cuboidal epithelium nor repopulation of the Bowman capsule or the glomerulus was observed. H\&E staining of scaffolds in which NS cells were cultured with epithelial medium showed the presence of simple, cuboidal, epithelial-like cells (Figure 4C) located in the tubular spaces and squamous endothelial-like cells (Figure 4C) located in the big vessels. Ki-67 staining, performed on sections processed after 15, 23, and 30 days of culture, proved the proliferative capacity of these cells. A 


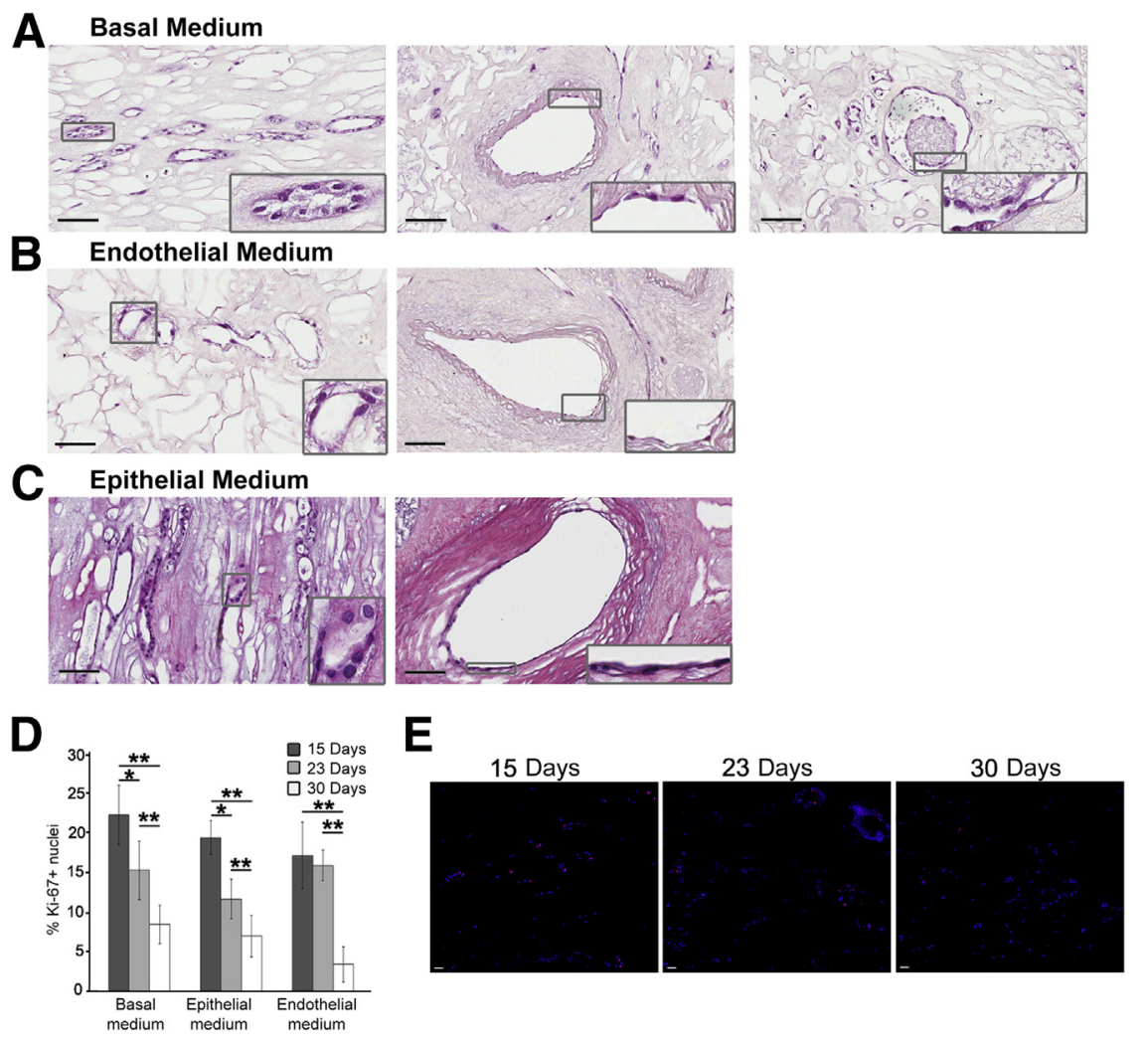

Figure 4 Histological characterization of the scaffold repopulated with nephrosphere (NS) cells. Ten independent experiments were performed. A-C: Representative hematoxylin and eosin staining of scaffold sections 30 days after seeding NS cells in the presence of the following: basal medium (A), endothelial medium (B), and epithelial medium (C). Insets: Boxed areas shown at $3 \times$ digital magnification. D: Percentage of immunofluorescence $\mathrm{Ki}-67-$ positive nuclei with respect to the total number of nuclei stained with DAPI. Section scaffolds evaluated at 15, 23, and 30 days after seeding the NS cells in the presence of the indicated media. E: Representative immunofluorescence analysis of the formalin-fixed, paraffin-embedded scaffolds repopulated with NS in basal medium at 15, 23, and 30 days with Ki-67 antibody. Data are expressed as means \pm SEM (D). ${ }^{*} P<0.05,{ }^{*} P<0.01$. Scale bars: $100 \mu \mathrm{m}(\mathbf{A}, \mathbf{B}$, left panel, $\mathbf{C}$, and $\mathbf{E}) ; 50 \mu \mathrm{m}$ (B, right panel).

reduction of their proliferative status during the culture with the three different media was observed (Figure 4, D and E); in particular, at 30 days, the reduction of proliferation was significant compared with 15 and 23 days. Moreover, we do not observe a significant increase of apoptosis, evaluated by cleaved caspase 3 expression, at different time points and a decline in cell population over time as a consequence (Supplemental Figure S2). NS cells cultured with basal medium seemed to have a better proliferation trend, although not significant, with respect to the other culture conditions.

Of note, although we started from tissue specimens derived from patients of different ages, no difference in differentiation plasticity based on age of cell and scaffold donors was observed.

\section{Characterization of Repopulated Scaffolds}

To investigate whether NS cells underwent differentiation to phenotypes of specific nephron compartments when seeded in the decellularized scaffolds, the expression of specific differentiation markers at 30 days, the time point that showed a proliferative behavior similar to tubular cells in renal tissue, was analyzed. The expression of CK8.18, known to be expressed by epithelial cells through the whole nephron, ${ }^{28}$ the proximal tubular marker CD10, the distal tubular marker CK7, and the endothelial marker vWf, was studied.
NS cells cultured on the scaffolds with basal medium for 30 days were able to generate proximal and distal tubular structures as well as endothelial-like structures (Figure 5). Tubular structures expressed CK8.18, and, in a mutually exclusive way, proximal CD10 (Figure 5A) or distal CK7 (Figure 5B) and distal E-cadherin or proximal N-cadherin (Supplemental Figure S3A). As expected, the structures did not present any Ki-67 signal (Figure 5A). Endothelial vWf was not detectable in the structures expressing tubular markers (Figure 5A). Instead, some of the structures that presented an endothelial-like morphology expressed endothelial vWf, while lacking the expression of CK8.18, CK7 (Figure 5A), and CD10 (data not shown). We also wanted to assess whether the structures expressing endothelial mature markers were correctly located in the correct vascular spaces. Exploiting the typical laminin pattern observed in the vascular basement membrane, which is different with respect to tubular ECM (Supplemental Figure S1, A and B), we evidenced that, in the repopulated ECM scaffold, all of the vWf-positive structures were localized in places where the laminin pattern was concentrated and organized like in the vessels (Supplemental Figure S1C).

NS cells cultured in basal medium also attached and proliferated into the glomerular space. These cells expressed the epithelial marker CK8.18, and they also had a weak expression of CD133, known to be expressed on the parietal cells of the Bowman capsule ${ }^{29}$ and, although highly debated, indicated as a marker of renal progenitors (Supplemental 


\section{A Basal medium}
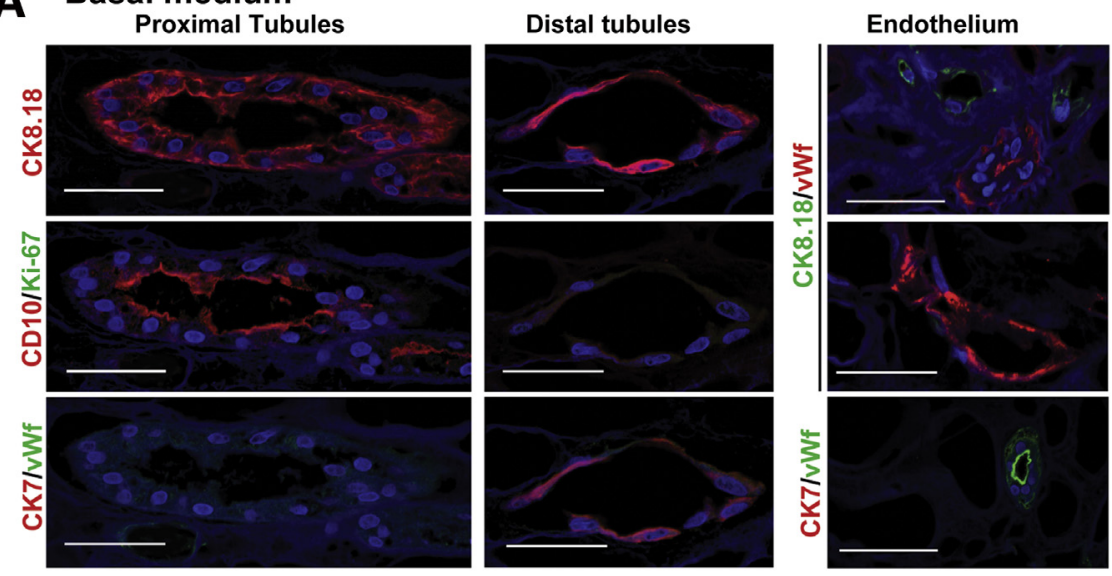

\section{B Endothelial medium}
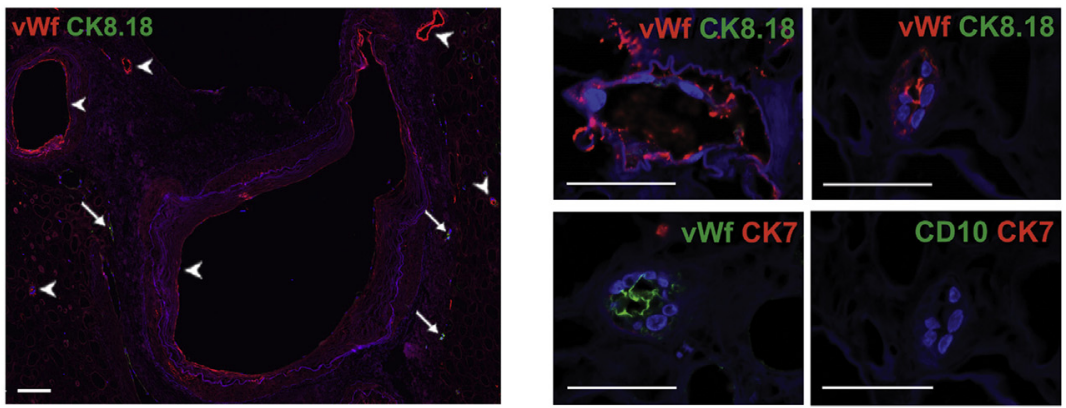

\section{Epithelial medium}
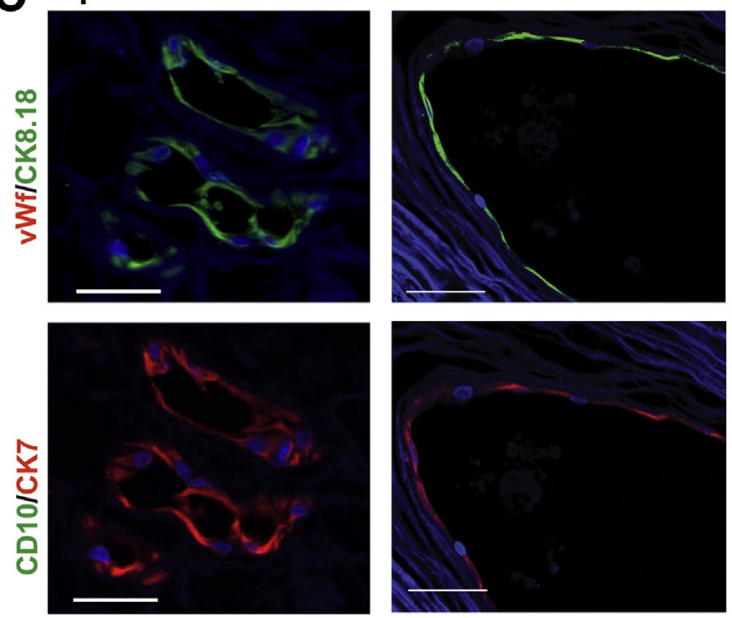

Figure 5 Characterization of the scaffolds repopulated with nephrosphere (NS) cells in the presence of basal (A), endothelial (B), and epithelial (C) media at 30 days. Representative immunofluorescence analysis of the formalin-fixed, paraffin-embedded scaffolds with the indicated antibodies able to recognize specific tubular or vascular phenotypes. Ten independent experiments were performed. A: The different antibody combinations in proximal tubules (left column), distal tubules (middle column), and endothelium (right column). B: Mostly endothelium (arrowheads) and a few epithelial cells (arrows). C: Distal tubular epithelial cells. Sequential immunostaining has been performed in the representative left and middle columns in $A$, right panels in $\mathbf{B}$, and all panels in C. Blue: DAPI. Scale bars: 50 $\mu \mathrm{m}(\mathbf{A}, \mathbf{B}$, right panels, and $\mathbf{C}) ; 100 \mu \mathrm{m}$ (B, left panel). CK, cytokeratin; vWf, von Willebrand factor.
Figure S3B). CD133 was not expressed by the newly repopulated tubular structures of the decellularized renal scaffold (data not shown). The cells that repopulated the glomerular space did not express the endothelial vWf and the podocyte synaptopodin and nephrin markers (Supplemental Figure S3B). Therefore, NS cells cultured on the scaffold without specific factors added to the medium differentiated toward an epithelial lineage, proximal and distal tubular cells, and an endothelial lineage.

Most of the structures generated by NS cells cultured on the scaffold with endothelial medium did not express epithelial CK8.18, but they did express endothelial vWf (Figure 5B). In addition, the coexpression of CK7 or CD10 and vWf on the same structure was not observed (Figure 5B). These data indicated that endothelial medium could induce NS differentiation mainly toward an endothelial lineage, generating endothelial-like structures (Figure 5B), although a few epithelial structures $\left(\mathrm{CK} 8.18^{+} / \mathrm{vWf}^{-}\right)$were present (Figure 5B). NS cells cultured on the scaffolds with epithelial medium only generated structures expressing epithelial markers. No expression of vWf was detected; however, all of the structures expressed CK8.18 (Figure 5C), even when the cells were localized in a vascular space presenting a squamous endothelial-like morphology (Figure 5C). Moreover, in 

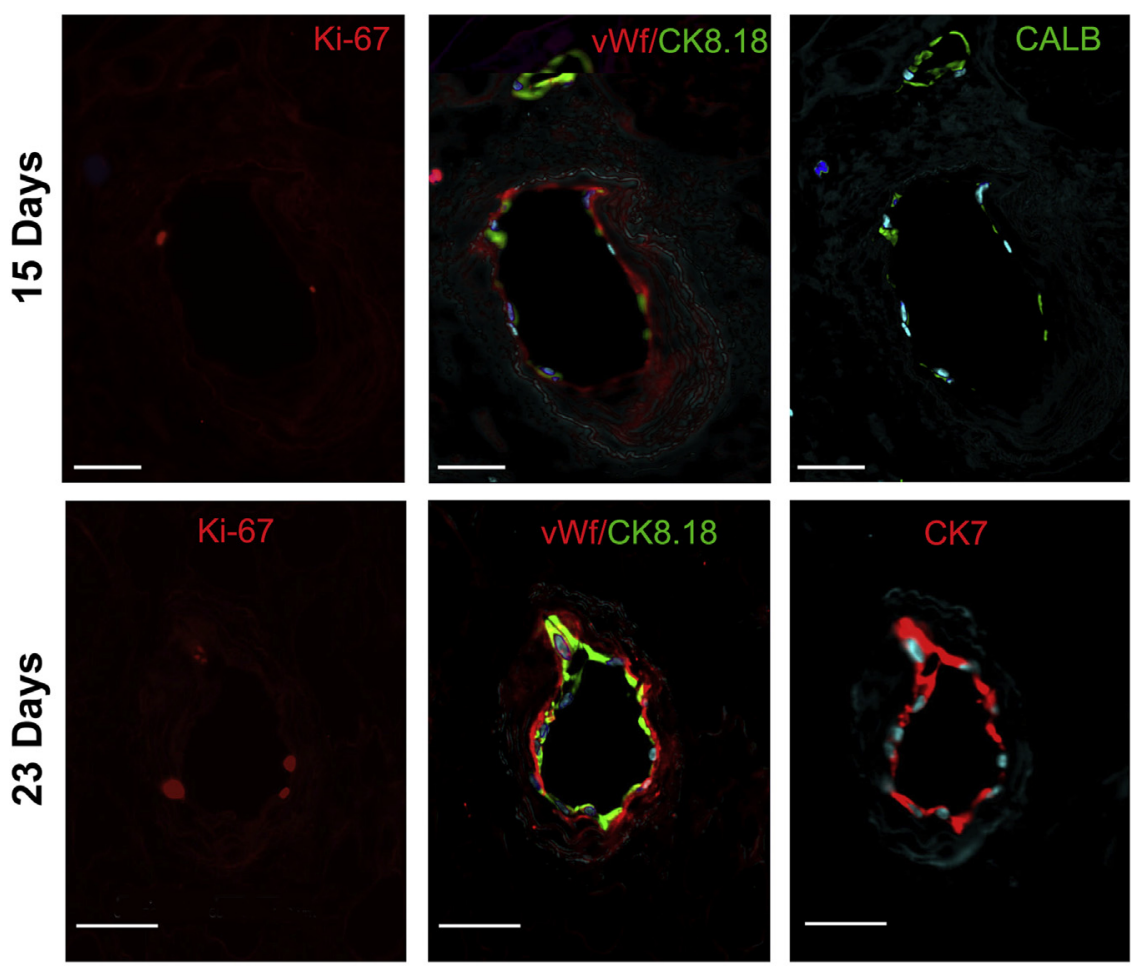

Figure 6 Representative sequential immunofluorescence staining of the formalin-fixed, paraffin-embedded scaffold repopulated with nephrosphere in basal medium at 15,23, and 30 days with the indicated antibodies. Yellow/orange signal in the bottom right panel indicates the coexpression of the distal markers calbindin-D28k (CALB) and cytokeratin (CK) 7. Light blue: DAPI. Scale bars $=50 \mu \mathrm{m}$. vWf, von Willebrand factor.
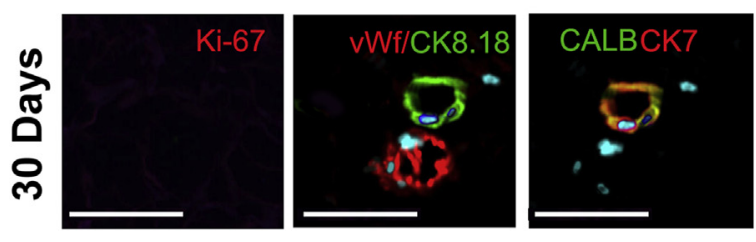

our studied cases, the structures expressed distal CK7 (Figure 5C), indicating a differentiation toward a distal tubular lineage.

The expression of differentiation markers in the presence of basal medium, the culture condition able to induce the different phenotypes, was studied at different time points. At 15 days, all of the studied markers were already expressed; interestingly, at 15 and 23 days in some structures, expressing Ki-67, the cells coexpressed epithelial (CK8.18), endothelial (vWf), and distal (CK7 and calbindin-D28k) tubular markers (Figure 6). This phenomenon was always absent at 30 days, when the cells in endothelial structures expressing vWf never expressed epithelial CK8.18 and CK7 and vice versa (Figure 6).

\section{Characterization of Nephrosphere Cells}

We investigated whether the cells into the NS had already entered a specific differentiation pathway, which would indicate if they were already committed at the moment of seeding on the scaffold. The expression of renal embryonic, epithelial, proximal, and distal tubular and endothelial markers has been studied. NS cells were positive for renal embryonic marker PAX2, demonstrating the renal origin of sphere cells, as we previously described. ${ }^{21}$ These NS cells coexpressed proximal tubular marker $\mathrm{N}$-cadherin and distal tubular marker E-cadherin (Figure 7A). Instead, these two markers, specific for different tubular portions, were never expressed together in the tubular structures generated by the NS cells when cultured on scaffolds with basal medium (Supplemental Figure S3A), mimicking the adult renal tissue and the differentiated tubular primary cell cultures. ${ }^{30-33}$ Although, by immunofluorescence on the spheres, most of the cells within the NS expressed the distal marker CK7 (Figure 7A), the proximal marker CD10 was almost nondetectable (data not shown). FACS analysis highlighted the coexpression of these two markers in NS cells. In fact, approximately $7 \%$ were $\mathrm{CK} 7^{+} / \mathrm{CD} 10^{+}$. Moreover, FACS analysis also confirmed the coexpression of other different proximal (CD13) and distal (prominin 2) tubular markers: approximately $9 \%$ of the cells were $\mathrm{CD} 13^{+} /$prominin $2^{+}$. Approximately $40 \%$ of $\mathrm{CD}^{+} 3^{+} / \mathrm{CD}^{-} 0^{-}$cells and approximately $5 \%$ of $\mathrm{CD}^{-} 3^{-} / \mathrm{CD} 10^{+}$cells, two phenotypes absent in mature proximal tubular cells that are supposed to coexpress both these proximal markers, were observed (Figure $7 \mathrm{~B}$ ). Although $11 \%$ of cells were $\mathrm{CD} 13^{+} / \mathrm{CD} 10^{+}$ (Figure 7B), approximately $75 \%$ of them coexpressed also the distal CK7 marker (Supplemental Figure S3C). 

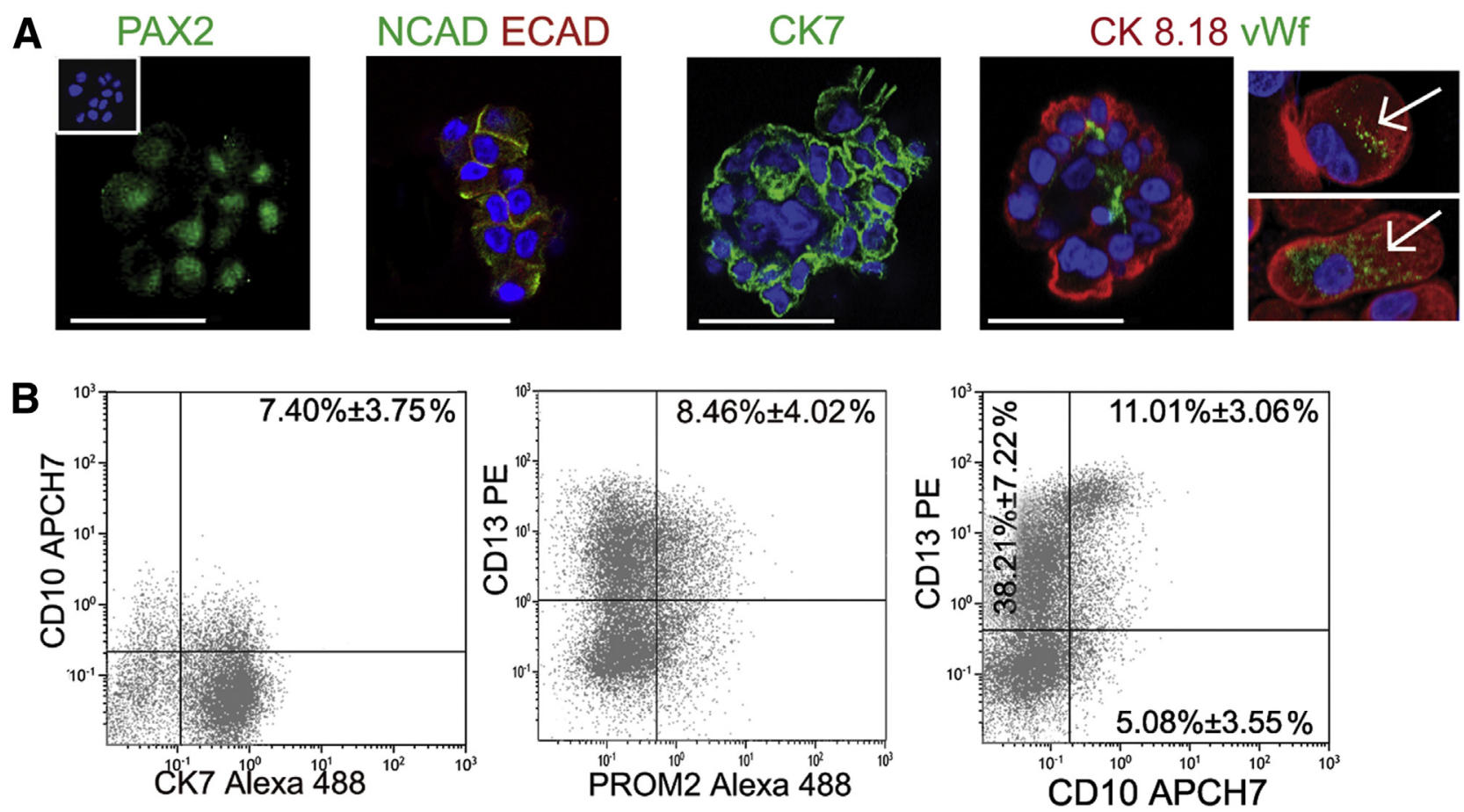

Figure 7 Immunophenotypical characterization of nephrospheres (NSs) cultured in sphere-forming conditions. A: Immunofluorescence analysis of NSs with the indicated antibodies. For the PAX2 panel, the DAPI signal is in the inset. The arrows indicate the NS cells that coexpress cytokeratin (CK) 8.18 and von Willebrand factor (vWf). Yellow: colocalization of red and green signals of E-cadherin and N-cadherin, respectively. Blue: DAPI. B: Fluorescence-activated cell sorting analysis of NS cells with the indicated antibodies. Data are expressed as means \pm SD of positive cells (B). $n \geq 3$ independent experiments (A and B). Scale bars $=50 \mu \mathrm{m}($ A). Original magnification, $\times 400$ (A). ECAD, E-cadherin; NCAD, N-cadherin; PE, phosphatidylethanolamine; PROM2, prominin 2.

Interestingly, in the whole sphere, some cells seemed to coexpress both epithelial CK8.18 and endothelial vWf markers, as immunofluorescence on cytospinned cells dissociated from the NS confirmed (Figure 7A). All these data indicated that cells of different phenotypes were present in the spheres, and the cells were not yet committed to a specific differentiation lineage before seeding on decellularized scaffolds.

\section{Discussion}

The advancement in stem cell research has contributed to knowledge regarding the possibility of developing and regenerating organs or tissues from a single cell. Significant progress has been made in the production and optimization of decellularization protocols, facilitating the complete removal of resident cells and preservation of ECM complexity to obtain kidney scaffolds. Advantageous sources of decellularized scaffolds can be kidneys of pigs, ${ }^{3,6,8-10}$ kidneys of nonhuman primates, ${ }^{11,12}$ and cadaveric human kidneys ${ }^{3}$ unsuitable for transplantation. ${ }^{13-15}$ However, these scaffolds are yet to be tested for their compatibility for transplantation in humans. One of the challenges is now the identification of the ideal cell types that can be successfully used in a recellularization process in human renal scaffolds. Multipotent human renal stem/progenitor cells, which could potentially be the right candidates for repopulation attempts, have never been tested on decellularized scaffolds. Although it has been reported by lineage tracing experiments that, at least in mice, lineage-restricted progenitors exist, ${ }^{34}$ herein we have shown the capacity of NS cells that coexpress markers of different lineages to repopulate different nephron portions of decellularized human renal scaffolds comprising cortex, medulla, and papilla. NS cells cultured on scaffolds with basal medium, without specific growth factors, were able to generate proximal and distal tubular structures as well as endotheliallike structures expressing the specific differentiation markers. Furthermore, they were able to attach and proliferate in the peripheral areas of the glomerular space but not in the inner glomerular endothelium or epithelium. We directly seeded NS cells on decellularized slices in a static system, and the capillary matrix structure inside the glomerulus may represent a physical obstacle for cell integration. The lack of glomerular endothelium can also explain the absence of visceral epithelium in the glomerulus. In fact, it is described ${ }^{35}$ that after establishment of the vasculature, endothelial cells appear responsible for a signal inducing the final maturation of podocytes.

Although repopulating vascular spaces, NS cells, when cultured with epithelial medium, were only able to generate epithelia expressing proximal or distal tubular markers but not endothelial markers. On the contrary, NS cells cultured with endothelial medium mainly generated endothelial-like structures that did not express epithelial tubular markers. These data indicated that NS cells were able to respond 
to differentiation stimuli present in epithelial (epidermal growth factor and hepatocyte growth factor) and endothelial (vascular endothelial growth factor) media that, likely, cooperate with the ECM signals amplifying the differentiation stimuli, and inducing only a specific differentiation lineage. Interestingly, when growth factors or external stimuli were not present in the medium (basal medium), NS cells were forced to differentiate, likely responding to stimuli retained in the ECM that may sustain cellular viability and proliferation. Our findings were in agreement with published observations describing that decellularized scaffolds, in addition to ECM composition, preserve growth factors, such as vascular endothelial growth factor, hepatocyte growth factor, connective tissue growth factor, plateletderived growth factor, insulin-like growth factor, and transforming growth factor- $\beta$. ${ }^{5,6,36}$ Moreover, the basement membrane and the underlying ECM have also been recently described to provide signals capable of influencing polarization and differentiation of human renal progenitors. ${ }^{37}$

One of the critical points in the recellularization process is the reconstitution of the vascular tree that, until now, has been obtained using human umbilical vein endothelial cells ${ }^{3}$ or human iPS-derived endothelial cells. ${ }^{6,20}$ The recently published article of $\mathrm{Du}$ et $\mathrm{al}^{20}$ is of particular interest because it describes the importance of the parenchymal and endothelial cells to be genetically identical for the establishment of the fundamental cell-cell interactions that contribute to the final kidney function. The only other examples of progressive expression of renal lineage markers and endothelial markers have been obtained with murine or human embryonic stem cells in rat or monkey decellularized scaffolds, respectively; however, a complete differentiation process was not observed. ${ }^{4,19}$ Herein, we have described, for the first time, the capability of an adult human renal stem/ progenitor-like cell population, obtained from clonal NS cells of individual subjects, ${ }^{21}$ to spontaneously differentiate into parenchymal and endothelial cell populations. Another group, using cells from nonclonal spheroids obtained from kidney tissue, was also able to produce tubular structures on chorioallontoic membrane, but these cells were not tested on decellularized kidney scaffolds. ${ }^{38}$ In our repopulated scaffolds at 15 and 23 days of culture, we can still observe coexpressions of markers of different lineages, typical of undifferentiated status, as seen in the NS grown in sphereforming conditions ${ }^{21}$ and in cells before seeding. At 30 days of culture, these coexpressions were no longer noted, as in adult renal tissue, and this underlines the timedependent role of ECM in cell differentiation. In conclusion, the capacity of NS cells to recreate tubular epithelial and endothelial structures in human renal decellularized scaffolds, together with their previously described differentiation capacity in two-dimensional and 3D in vitro cultures and in vivo under the murine renal capsule, ${ }^{21}$ make these cells promising for kidney recellularization and regenerative studies. The data obtained herein can provide a foundation for experimental investigations focused on the study of parenchymal and endothelial cell-cell interactions in models of whole kidney reconstruction to prospectively generate completely functional nephrons that are capable of filtration and reabsorption.

\section{Acknowledgments}

We thank Andrew Smith and Maureen Quinn for English revision and Maddalena Bolognesi for technical support with the Hamamatsu Nanozoomer S60 scanner.

\section{Supplemental Data}

Supplemental material for this article can be found at https://doi.org/10.1016/j.ajpath.2017.09.012.

\section{References}

1. Jha V, Garcia-Garcia G, Iseki K, Li Z, Naicker S, Plattner B, Saran R, Wang AY, Yang CW: Chronic kidney disease: global dimension and perspectives. Lancet 2013, 382:260-272

2. Bussolati B, Camussi G: Therapeutic use of human renal progenitor cells for kidney regeneration. Nat Rev Nephrol 2015, 11:695-706

3. Song JJ, Guyette JP, Gilpin SE, Gonzalez G, Vacanti JP, Ott HC: Regeneration and experimental orthotopic transplantation of a bioengineered kidney. Nat Med 2013, 19:646-651

4. Bonandrini B, Figliuzzi M, Papadimou E, Morigi M, Perico N, Casiraghi F, Sangalli F, Conti S, Benigni A, Remuzzi A, Remuzzi G: Recellularization of well-preserved acellular kidney scaffold using embryonic stem cells. Tissue Eng Part A 2014, 20:1486-1498

5. Peloso A, Ferrario J, Maiga B, Benzoni I, Bianco C, Citro A, Currao M, Malara A, Gaspari A, Balduini A, Abelli M, Piemonti L, Dionigi P, Orlando G, Maestri M: Creation and implantation of acellular rat renal ECM-based scaffolds. Organogenesis 2015, 11:58-74

6. Caralt M, Uzarski JS, Iacob S, Obergfell KP, Berg N, Bijonowski BM, Kiefer KM, Ward HH, Wandinger-Ness A, Miller WM, Zhang ZJ, Abecassis MM, Wertheim JA: Optimization and critical evaluation of decellularization strategies to develop renal extracellular matrix scaffolds as biological templates for organ engineering and transplantation. Am J Transplant 2015, 15:64-75

7. O'Neill JD, Freytes DO, Anandappa AJ, Oliver JA, VunjakNovakovic GV: The regulation of growth and metabolism of kidney stem cells with regional specificity using extracellular matrix derived from kidney. Biomaterials 2013, 34:9830-9841

8. Orlando G, Farney AC, Iskandar SS, Mirmalek-Sani SH, Sullivan DC, Moran E, AbouShwareb T, De Coppi P, Wood KJ, Stratta RJ, Atala A, Yoo JJ, Soker S: Production and implantation of renal extracellular matrix scaffolds from porcine kidneys as a platform for renal bioengineering investigations. Ann Surg 2012, 256:363-370

9. Wang Y, Bao J, Wu Q, Zhou Y, Li Y, Wu X, Shi Y, Li L, Bu H Method for perfusion decellularization of porcine whole liver and kidney for use as a scaffold for clinical-scale bioengineering engrafts. Xenotransplantation 2015, 22:48-61

10. Sullivan DC, Mirmalek-Sani SH, Deegan DB, Baptista PM, Aboushwareb T, Atala A, Yoo JJ: Decellularization methods of porcine kidneys for whole organ engineering using a high-throughput system. Biomaterials 2012, 33:7756-7764

11. Nakayama KH, Batchelder CA, Lee CI, Tarantal AF: Decellularized rhesus monkey kidney as a three-dimensional scaffold for renal tissue engineering. Tissue Eng Part A 2010, 16:2207-2216 
12. Nakayama KH, Batchelder CA, Lee CI, Tarantal AF: Renal tissue engineering with decellularized rhesus monkey kidneys: age-related differences. Tissue Eng Part A 2011, 17:2891-2901

13. Orlando G, Booth C, Wang Z, Totonelli G, Ross CL, Moran E, Salvatori M, Maghsoudlou P, Turmaine M, Delario G, Al-Shraideh Y, Farooq U, Farney AC, Rogers J, Iskandar SS, Burns A, Marini FC, De Coppi P, Stratta RJ, Soker S: Discarded human kidneys as a source of ECM scaffold for kidney regeneration technologies. Biomaterials 2013, 34:5915-5925

14. Peloso A, Petrosyan A, Da Sacco S, Booth C, Zambon JP, O'Brien T, Aardema C, Robertson J, De Filippo RE, Soker S, Stratta RJ, Perin L, Orlando G: Renal extracellular matrix scaffolds from discarded kidneys maintain glomerular morphometry and vascular resilience and retains critical growth factors. Transplantation 2015, 99:1807-1816

15. Katari R, Peloso A, Zambon JP, Soker S, Stratta RJ, Atala A, Orlando G: Renal bioengineering with scaffolds generated from human kidneys. Nephron Exp Nephrol 2014, 126:119

16. Ross EA, Williams MJ, Hamazaki T, Terada N, Clapp WL, Adin C, Ellison GW, Jorgensen M, Batich CD: Embryonic stem cells proliferate and differentiate when seeded into kidney scaffolds. J Am Soc Nephrol 2009, 20:2338-2347

17. Ross EA, Abrahamson DR, St John P, Clapp WL, Williams MJ, Terada N, Hamazaki T, Ellison GW, Batich CD: Mouse stem cells seeded into decellularized rat kidney scaffolds endothelialize and remodel basement membranes. Organogenesis 2012, 8:49-55

18. Guan Y, Liu S, Sun C, Cheng G, Kong F, Luan Y, Xie X, Zhao S, Zhang D, Wang J, Li K, Liu Y: The effective bioengineering method of implantation decellularized renal extracellular matrix scaffolds. Oncotarget 2015, 6:36126-36138

19. Batchelder CA, Martinez ML, Tarantal AF: Natural scaffolds for renal differentiation of human embryonic stem cells for kidney tissue engineering. PLoS One 2015, 10:e0143849

20. Du C, Narayanan K, Leong MF, Ibrahim MS, Chua YP, Khoo VMH, Wan ACA: Functional kidney bioengineering with pluripotent stemcell-derived renal progenitor cells and decellularized kidney scaffolds. Adv Healthc Mater 2016, 5:2080-2091

21. Bombelli S, Zipeto MA, Torsello B, Bovo G, Di Stefano V, Bugarin C, Zordan P, Viganò P, Cattoretti G, Strada G, Bianchi C, Perego RA: $\mathrm{PKH}^{\text {high }}$ cells within clonal human nephrospheres provide a purified adult renal stem cell population. Stem Cell Res 2013, 11:1163-1177

22. Bianchi C, Bombelli S, Raimondo F, Torsello B, Angeloni V, Ferrero S, Di Stefano V, Chinello C, Cifola I, Invernizzi L, Brambilla P, Magni F, Pitto M, Zanetti G, Mocarelli P, Perego RA: Primary cell cultures from human renal cortex and renal-cell carcinoma evidence a differential expression of two spliced isoforms of annexin A3. Am J Pathol 2010, 176:1660-1670

23. Di Stefano V, Torsello B, Bianchi C, Cifola I, Mangano E, Bovo G, Cassina V, De Marco S, Corti R, Meregalli C, Bombelli S, Viganò P, Battaglia C, Strada G, Perego RA: Major action of endogenous lysyl oxidase in clear cell renal cell carcinoma progression and collagen stiffness revealed by primary cell cultures. Am J Pathol 2016, 186:2473-2485

24. Bacci S, Pieri L, Buccoliero AM, Bonelli A, Taddei G, Romagnoli P: Smooth muscle cells, dendritic cells and mast cells are sources of TNFalpha and nitric oxide in human carotid artery atherosclerosis. Thromb Res 2008, 122:657-667
25. Scalia CR, Gendusa R, Cattoretti G: A 2-step Laemmli and antigen retrieval method improves immunodetection. Appl Immunohistochem Mol Morphol 2016, 24:436-446

26. Gendusa R, Scalia CR, Buscone S, Cattoretti G: Elution of highaffinity (>10-9 KD) antibodies from tissue sections: clues to the molecular mechanism and use in sequential immunostaining. J Histochem Cytochem 2014, 62:519-531

27. Boi G, Scalia CR, Gendusa R, Ronchi S, Cattoretti G: Disaccharides protect antigens from drying-induced damage in routinely processed tissue sections. J Histochem Cytochem 2016, 64:18-31

28. Skinnider BF, Folpe AL, Hennigar RA, Lim SD, Cohen C, Tamboli P, Young A, de Peralta-Venturina M, Amin MB: Distribution of cytokeratins and vimentin in adult renal neoplasms and normal renal tissue: potential utility of a cytokeratin antibody panel in the differential diagnosis of renal tumors. Am J Surg Pathol 2005, 29:747-754

29. Sagrinati C, Netti GS, Mazzinghi B, Lazzeri E, Liotta F, Frosali F, Ronconi E, Meini C, Gacci M, Squecco R, Carini M, Gesualdo L, Francini F, Maggi E, Annunziato F, Lasagni L, Serio M, Romagnani S, Romagnani P: Isolation and characterization of multipotent progenitor cells from the Bowman's capsule of adult human kidneys. J Am Soc Nephrol 2006, 17:2443-2456

30. Nouwen EJ, Dauwe S, van der Biest I, De Broe ME: Stage- and segment-specific expression of cell-adhesion molecules N-CAM, ACAM, and L-CAM in the kidney. Kidney Int 1993, 44:147-158

31. Prozialeck WC, Lamar PC, Appelt DM: Differential expression of Ecadherin, $\mathrm{N}$-cadherin and beta-catenin in proximal and distal segments of the rat nephron. BMC Physiol 2004, 4:10

32. Keller C, Kroening S, Zuehlke J, Kunath F, Krueger B, GoppeltStruebe M: Distinct mesenchymal alterations in N-cadherin and Ecadherin positive primary renal epithelial cells. PLoS One 2012, 7: e43584

33. Torsello B, Bianchi C, Meregalli C, Di Stefano V, Invernizzi L, Bovo G, Brivio R, Strada G, Bombelli S, Perego RA: Arg tyrosine kinase modulates TGF- $\beta 1$ production in human renal tubular cells under high glucose conditions. J Cell Sci 2016, 29:2925-2936

34. Rinkevich Y, Montoro DT, Contreras-Trujillo H, Harari-Steinberg O, Newman AM, Tsai JM, Lim X, Van-Amerongen R, Bowman A, Januszyk M, Pleniceanu O, Nusse R, Longaker MT, Weissman IL, Dekel B: In vivo clonal analysis reveals lineage-restricted progenitor characteristics in mammalian kidney development, maintenance, and regeneration. Cell Rep 2014, 7:1270-1283

35. Pavenstädt H, Kriz W, Kretzler M: Cell biology of the glomerular podocyte. Physiol Rev 2003, 83:253-307

36. Yu YL, Shao YK, Ding YQ, Lin KZ, Chen B, Zhang HZ, Zhao LN, Wang ZB, Zhang JS, Tang ML, Mei J: Decellularized kidney scaffoldmediated renal regeneration. Biomaterials 2014, 35:6822-6828

37. Sciancalepore AG, Portone A, Moffa M, Persano L, De Luca M, Paiano A, Sallustio F, Schena FP, Bucci C, Pisignano D: Micropatterning control of tubular commitment in human adult renal stem cells. Biomaterials 2016, 94:57-69

38. Buzhor E, Harari-Steinberg O, Omer D, Metsuyanim S, JacobHirsch J, Noiman T, Dotan Z, Goldstein RS, Dekel B: Kidney spheroids recapitulate tubular organoids leading to enhanced tubulogenic potency of human kidney-derived cells. Tissue Eng Part A 2011, 17:2305-2319 